\title{
Monocanalicular versus bicanalicular intubation in the treatment of congenital nasolacrimal duct obstruction
}

\author{
Pavel Komínek • Stanislav Červenka • Tomáš Pniak • \\ Karol Zeleník • Hana Tomášková • Petr Matoušek
}

Received: 8 November 2010 /Revised: 8 February 2011 /Accepted: 15 April 2011 / Published online: 17 June 2011

(C) The Author(s) 2011. This article is published with open access at Springerlink.com

\begin{abstract}
Background To compare the success rate of monocanalicular intubation (MCI) compared with bicanalicular silicone intubation (BCI) in congenital nasolacrimal duct obstruction (CNLDO) in infants and toddlers.

Methods In a prospective, nonrandomized, comparative study, MCI ( $n=35$ eyes) through the inferior canaliculus or BCI $(n=35$ eyes) were performed under general anaesthesia in children aged 10 to 36 months with CNLDO. The tubes were removed 3-4 months after tube placement, and the children were followed up for 6 months after the removal of tubes. Therapeutic success was defined as the fluorescein dye disappearance test grade $0-1$, corresponding with a complete resolution of previous symptoms. Partial success was defined as improvement with some residual symptoms. Results Complete and partial improvement was achieved in $31 / 35(88.57 \%)$ in the BCI group and 34/35 (97.14\%) in the MCI group. The difference between the two groups was not significant $(p=0.584)$. Complications occurred in both groups. Dislodgement of the tube and premature removal
\end{abstract}

Electronic supplementary material The online version of this article (doi:10.1007/s00417-011-1700-2) contains supplementary material, which is available to authorized users.

P. Komínek $(\bowtie) \cdot S$. Červenka $\cdot$ T. Pniak $\cdot K$. Zeleník

P. Matoušek

Department of Otolaryngology, University Hospital Ostrava,

17. listopadu Street 1790 ,

708 52, Ostrava, Czech Republic

e-mail: pavel.kominek@fno.cz

S. Červenka

Department of Ophthalmology,

Otrokovice, Czech Republic

H. Tomášková

Department of Epidemiology and Public Health, Faculty of Health

Studies, University of Ostrava,

Ostrava, Czech Republic was observed in four BCI cases, and loss of the tube was observed twice in the MCI group. Canalicular slitting was observed in five eyes in the BCI group. Granuloma pyogenicum observed in 2 cases with MCI revealed a few weeks after the tube removal. Corneal erosion in the inferior medial quadrant was observed in one $\mathrm{MCI}$ eye and revealed in a few days after the local treatment without tube removal. Conclusions Both MCI and the BCI are effective methods for treating CNLDO. MCI has the advantage of a lower incidence of canalicular slit and easy placement.

Keywords Congenital nasolacrimal duct obstruction . Monocanalicular intubation - Bicanalicular intubation . Complications · Lacrimal

\section{Introduction}

Silicone intubation of the lacrimal system has become very popular in the treatment of congenital nasolacrimal duct obstructions (CNLDO) resistant to conservative therapy and/or probing [1-6]. Bicanalicular intubation (BCI) has been used since the 1970s, and various techniques have been described, whereas monocanalicular intubation (MCI) was not popular until the early 1990s [1, 6-8].

Each of these intubation systems has advantages and disadvantages $[2,3,5-7,9]$. Whereas the bicanalicular system requires passing a tube through the inferior and superior puncta and through the lacrimal system into the nose, the monocanalicular system requires a single pass of the tube through the system $[1,2,4]$. Nevertheless, a comparison of the two kinds of intubation to determine which is optimal has not been well-performed so far. The objective of this study was to compare the success rate and complications of $\mathrm{MCI}$ and $\mathrm{BCI}$ in children treated for CNLDO. 


\section{Materials and methods}

\section{Study design}

The aim of this prospective study was to compare the success rate of MCI and BCI silicone intubations in the treatment of children with CNLDO. The study was performed in accordance with the Declaration of Helsinki, Good Clinical Practice, and applicable regulatory requirements. Informed written consent was obtained from all parents/guardians before the initiation of any procedure.

Children aged between 12 and 36 months with severe CNLDO symptoms resistant to conservative therapy and two probings were included in the study. The diagnosis of CNLDO was based on a history of tearing, the fluorescein dye disappearance test (FDT), and diagnostic probing and/or irrigation tests. The study was carried out from January 2006 to November 2009, and a total of 70 eyes (in 53 children) were included.

Children younger than 10 months of age were excluded because of known self-resolution during maturation of the nasolacrimal duct. Patients with previous eyelid and/or lacrimal surgery, punctal and/or canalicular obstructions, eyelid malpositioning, and less than 6 months follow-up were also excluded.

Time points and follow up clinical examinations

The study started with 35 consecutive cases of BCI (group I) followed by 35 consecutive cases of MCI (group II). The silicone tubes were removed 3 to 4 months after the surgery, and the children were followed up for 6 months.

The drainage function of the lacrimal system was assessed using a combination of the FDT, medical history and clinical examinations (tear retention and conjunctival sac evaluation, medial canthus observation and/or palpation), as well as syringing of the system in some cases, as required. However, the history and the FDT were considered to be the major endpoints.

Complete therapeutic success was defined as FDT grade $0-1$, and this result had to correspond with a complete resolution of previous symptoms. Partial success was defined as FDT 0-1 with substantial improvement and some residual symptoms. Failure was defined as the absence of improvement or the worsening of the symptoms.

For the statistical analysis $\chi^{2}$-test, Fisher's exact test, and the two-sample $t$-test were used, with the level of significance set at $p<0.05$.

Procedure technique

After probing the lacrimal pathways with the help of a Bowman probe, endoscopy of the inferior meatus with the help of a rigid Hopkins endoscope, $30^{\circ}$ and $2.7 \mathrm{~mm}$ in diameter, was performed after infraction of the inferior concha. If the probe was placed submucously, a focused incision of the mucous membrane was made, and the end of the probe was released in the inferior nasal meatus.

For intubations, bicanalicular and monocanalicular silicone sets were used (ELLA-CS, M. Horákové 504, 50006 Hradec Králové, Czech Republic, phone +420 495279111 , www.ellacs.cz).

After probing the lacrimal system through the inferior canaliculus with a metal probe in the bicanalicular set, a titanium sling was then put on the tip of the probe into the inferior meatus under endoscopic control, and the metal probe was pulled out of the nose by pulling the handle of the sling and pressing down on the ocular end of the probe [10]. After introducing the other probe of an intubation set into the lacrimal pathways through the upper lacrimal punctum, the probe was also pulled out of the inferior nasal meatus in the same way. The whole procedure was completed by knotting both tubes and placing the knot into the inferior nasal meatus.

For the monocanalicular intubation setting, the silicone tube (with the ocular anchor and flange) atraumatically connected with the metal rod was inserted through the lower canaliculus in a similar way (Fig. 1). The nasal end of the metal rod was then pulled into the nose and the ocular end of the tubing was fixed in the punctual ampulla and secured with a punctual anchor, while the tube was gently tracted on the distal (nasal) end. After punctual footplate placement, the distal end of the tubing was cut and left to dangle freely in the inferior nasal meatus.

When removing the BCI while the patient was under local anaesthesia, the silicone tube was removed after the knot had been drawn up through the lacrimal pathways into the conjuctival sac. The MCI was removed by pulling it out with forceps at the lacrimal punctum while the patient was under local anaesthesia.

\section{Results}

Seventy eyes of 53 patients were studied. Bicanalicular intubation was performed in 35 eyes ( 24 children; group I) and monocanalicular in 35 (29 children; group II). The youngest patient was 10 months of age and the oldest was 32 months of age (Fig. 2). Thirty-nine eyes were from female patients, and 31 from male patients. The right eye was involved in 39 cases. Tubes were usually removed between 3 and 4 months after the surgery in an office setting (Figs. 3, 4).

In group I, complete resolution of symptoms was observed in $29 / 35$ cases $(82.86 \%$ ), partial resolution in 2/ $35(5.71 \%)$, and failure in four cases $(11.43 \%)$ (Table 1$)$. In 
Fig. 1 Monocanalicular intubation set (ELLA-CS, Czech Republic) - in detail

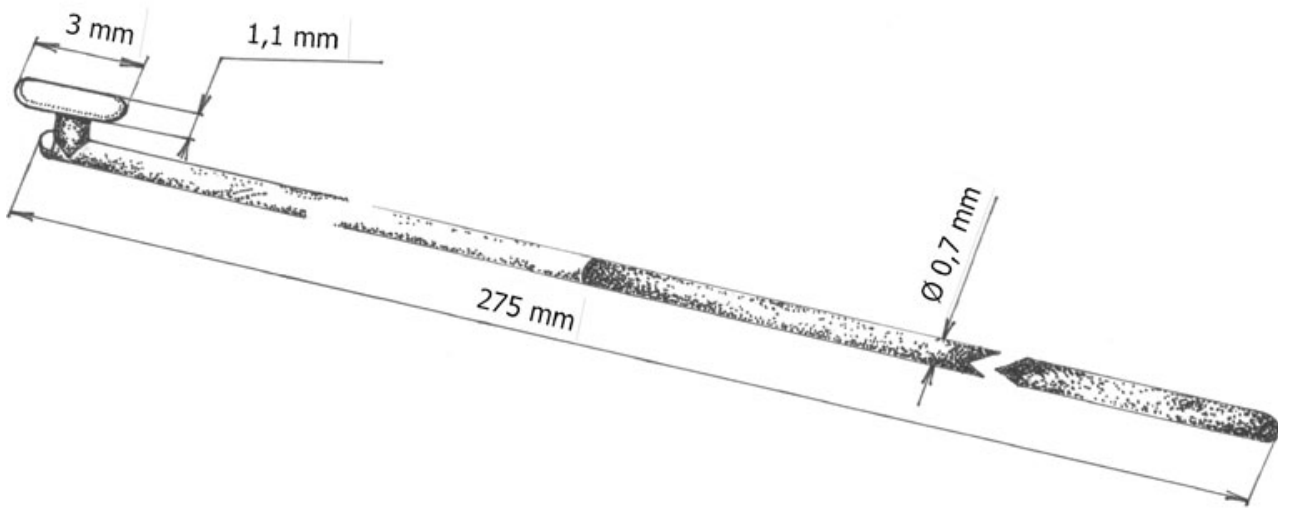

group II, the complete resolution of symptoms was observed in $31 / 35$ eyes ( $88.57 \%$ ), partial success in $3 / 35$ eyes $(8.57 \%)$, and failure in $1 / 35$ eyes $(2.86 \%)$. Therefore, complete and partial success was achieved in 31/35 (88.57\%) in group I and in 34/35 (97.14\%) in group II. The success rate (complete + partial success) in group II (MCI) was not significantly higher than that of group I (BCI) $(p=0.584)$. There was found no age nor sex predominance.

\section{Complications}

Dislodging of the tube and premature removal was observed in four cases in group I $(1,2,4$, and 8 weeks after intubation respectively), whereas loss of the tube was observed twice (1 week after intubation in one case, and in one case the parents did not specify the time of the loss) in group II (Table 2). In children with premature tube removal, improvement of symptoms was observed in $3 / 4$ eyes in group I $(75.0 \%)$, and in $2 / 2$ eyes in group II $(100.0 \%)$.

Slitting of the punctum and canaliculi were observed in five eyes with BCI (group I) and none with MCI (group II). Granuloma pyogenicum was found in two cases with MCI and completely revealed during 2 months after tube removal without any specific treatment.

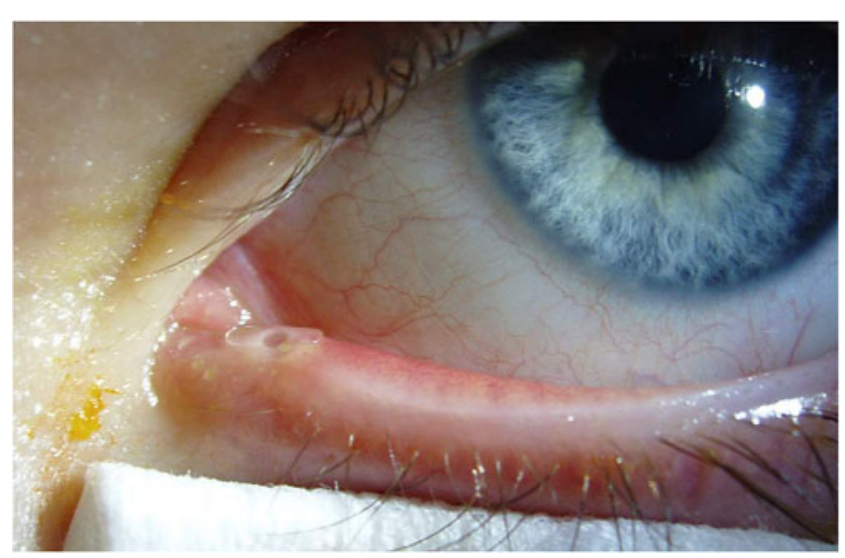

Fig. 2 Monocanalicular intubation showing the position of the flange on the eyelid margin after tube fixation
Corneal erosion in the inferior medial quadrant was observed in one eye treated with MCI shortly after tube placement, and resolved within a few days after local treatment; it was not necessary to remove the tube prematurely.

\section{Discussion}

Silicone intubation was first described by Quickert and Dryden in 1970 and the procedure has become part of the standard management of CNLDO [2, 3, 6]. Among the factors that affect the treatment success of CNLDO are age, severity of symptoms, the history of previous interventions, time of the interventions, and compliance with treatment. However, there are no generally accepted and defined rules concerning age, length of intubation, and/or different variations in intubation systems $[6,11]$.

Although tube placement in children requires general anesthesia, the normal anatomy of the lacrimal system is not destroyed, and the success rates range from $80 \%$ to $100 \%[1-3,6,12]$. BCI has been used more frequently, not only for treatment of CNLDO, but also for dacryocystorhinostomy, canalicular stenose, etc. [2, 6].

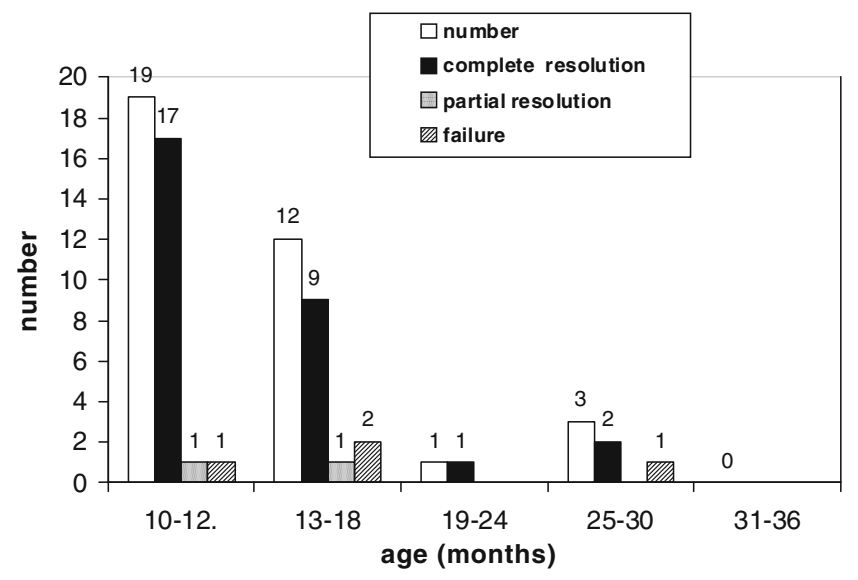

Fig. 3 Bicanalicular intubation in CNLDO; success rate according to age 


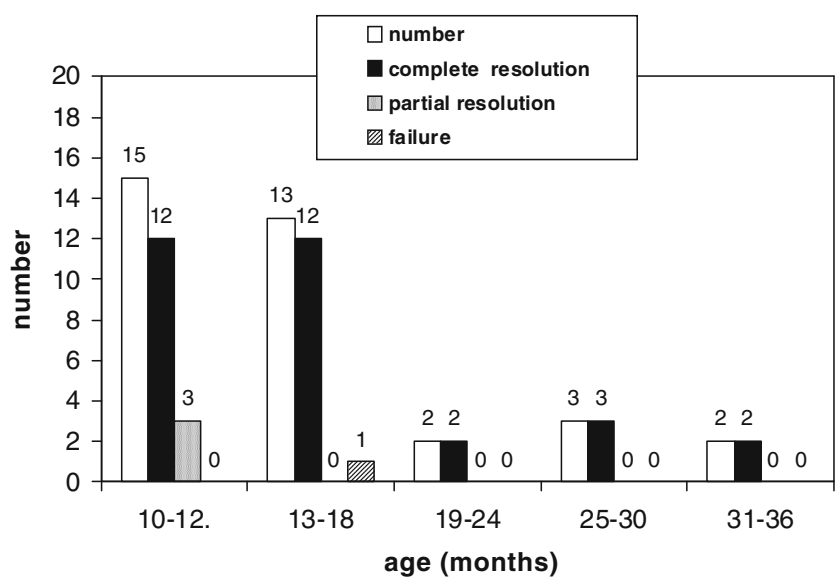

Fig. 4 Monocanalicular intubation in CNLDO; success rate according to age

One of the factors that may determine whether or not to use $\mathrm{BCI}$ or $\mathrm{MCI}$ is the number of complications $[1-3,6]$. One of the main advantages of $\mathrm{BCI}$ is that $\mathrm{BCI}$ is generally very well-tolerated by the cornea because it is significantly smoother than MCI $[1,7,9]$. If MCI is used, corneal abrasions or ulcers can be caused by the ocular end of the MCI. The abrasions usually occur in the inferior nasal quadrant (if the tube is fixed in the the inferior canaliculus), and usually heal in a few days after local treatment [9]. Fayet et al. observed only three $(1.5 \%)$ corneal ulcers in 223 eyes with MCI, whereas no corneal ulcers were observed in 1,620 BCI placements [9]. They assumed that the placement of the MCI in the superior canaliculus is a predisposing factor for corneal irritation, especially if the size and length of the collarete is larger [9]. On the other hand, Engel et al. recommend performing MCI through the superior canaliculus, and found only a $2 \%$ risk of conjunctival or corneal abrasions in their series of 635 eyes [3]. In our study, in which monocanalicular tubes were inserted into the inferior canaliculus, corneal abrasion was observed in only one child $(2.8 \%)$ a few days after the surgery. The abrasion healed within 3 days without the premature removal of the tube. Our experience confirms that it is necessary to use tubes of an appropriate size with a small flange (collar) that does not exceed the eyelid margin

Table 1 Comparison of the bicanalicular and monocanalicular intubation results

\begin{tabular}{|c|c|c|}
\hline Outcome & $\begin{array}{l}\text { Group I: } \\
\text { bicanalicular } \\
\text { intubation ( } 35 \text { cases) }\end{array}$ & $\begin{array}{l}\text { Group II: } \\
\text { monocanalicular } \\
\text { intubation ( } 35 \text { cases) }\end{array}$ \\
\hline Complete resolution & $29(82.86 \%)$ & $31(88.57 \%)$ \\
\hline Partial resolution & $2(5.71 \%)$ & $3(8.57 \%)$ \\
\hline Failure & $4(11.4 \%)$ & $1(2.86 \%)$ \\
\hline Total & $31 / 35(88.57 \%)$ & $34 / 35(97.14 \%)$ \\
\hline
\end{tabular}

Table 2 Comparison of the complications observed with bicanalicular (BCI) and monocanalicular intubation (MCI)

\begin{tabular}{lll}
\hline Complications/number & Group I BCI & Group II MCI \\
\hline $\begin{array}{l}\text { Displacement and premature } \\
\text { removal }\end{array}$ & 4 & - \\
Loss & - & 2 \\
Granuloma pyogenicum & - & 2 \\
Corneal abrasion/ulcer & - & 1 \\
Canalicular slitting & 5 & - \\
Inflammation of the lacrimal system & - & - \\
\hline
\end{tabular}

and does not irritate the cornea, so that corneal abrasion and ulceration is prevented. Conversely, Fayet et al. found the diameter of the collar to be unimportant and without influence on the rate of corneal erosions [7].

MCI offers a chance to achieve better success rates than simple probing, and requires only a single pass through the nasolacrimal system [3]. The technical insertion of MCI as well as its removal is easy, and the difficulties associated with BCI are minimized $[1,4]$. Based on our 17 years of experience with lacrimal surgery, we agree that the manipulation in only one canaliculus may be advantageous because the risk of possible iatrogenic traumatisation of the lacrimal system is lower.

Unexpected side-effects should be taken into consideration, too. While we observed no granuloma pyogenicum in the BCI group, we observed two granulomas in children who had MCI. Though these occurences resolved a few weeks after removal of the tube, they seem to be related to the ocular end of MCI. Fayet et al. recommended not leaving a MCI in for longer than 3 months to decrease the likelihood of complications [9]. While we usually removed MCIs within 3 to 4 months after placing the tubes, the question of whether or not the number of complications would increase with longer MCI placement is unclear. In our study, there were only two children with a longer (5 and 11 months respectively) tube placement (they did not return for removal of the tube until these times); however, no complications were observed in these two cases, and full success was achieved.

In order to prevent damage to the punctum and fibrous meatal ring while inserting the MCI, an appropriate technique should be used [7]. That is why performing an excessively aggressive dilation of the punctum is not recommended. Fayet, who developed the Monoka system (FCI, France), recommends only gentle traction on the distal end at the time of insertion and gentle dilation of the punctum $[7,9]$. A special dilator for inserting the tube can help to avoid inadvertent damage to the puntal and canalicular systems [7]. Although we did not use this dilator, no difficulties during the time of tubing were observed. 
On the other hand, excessive dilation might increase the incidence of some complications, especially spontaneous loss of the tubing [7]. This complication was observed in $35.4 \%$ in a study of 48 eyes with CNLDO treated with MCI reported by Kaufman and Guay-Bhatia, where premature removal was observed in 21 of 48 eyes (43.7\%) [1]. Our results did not confirm these findings. Dislodgement of BCI causing premature removal was observed in four eyes, whereas premature loss of the monocanalicular tube was observed twice.

Few reports compare the success rates of MCI with BCI. The success rates of BCIs for the treatment of CNLDO range from $83 \%$ to $100 \%[2,6,11,12]$. Feyet et al. observed complete resolution of epiphora in $67.7 \%$ with Monoka and $62.4 \%$ with BCI in their study of 120 cases [13]. In their study comparing MCI and BCI in 48 eyes of adults, Kashkouli et al. achieved nearly the same complete success rate (MCI 61.5\%, BCI 59.0\%); moreover, higher partial success and lower failure rate was achieved than in the group with BCI [4]. In our study, we found no significant differences in the sucess rates between the BCI (88.5\%) and MCI (97.1\%) groups. On the other hand, in the study by Kaufman et al. of 48 eyes with MCI, full and partial success was achieved in only 30 cases $(78.0 \%)$, and 21 cases of premature tube removal occurred (43.7\%) [1]. In the study by Engel et al. of 635 children with probing and MCI, the success rate was $97 \%$, declining to $90 \%$ when surgery was performed in infants older than 24 months of age [3]. We agree with Engel et al. that, for those patients with CNLDO requiring general anesthesia, MCI may reduce recurrence and reoperations, and is an appropriate alternative in the treatment of CNLDO [3].

Our results raise the question of whether or not it would be better to prefer MCI over BCI in the treatment of CNLDO. Although our study supports a preference for $\mathrm{MCI}$, further prospective, randomised studies would better determine the advantages and disadvantages of the two intubation methods.

\section{Conclusion}

$\mathrm{MCI}$ is very effective in the treatment of CNLDO, and is an appropriate alternative procedure with a minimum of complications. The success rates of $\mathrm{MCI}$ and $\mathrm{BCI}$ were not significantly different. The use of monocanalicular intubation is easier to perform; thus, it is a useful method for the treatment of CNLDO resistant to conservative therapy and probing.

Acknowledgment The authors would like to thank Mrs Zdena Závadová for her assistance with the manuscript.
Meeting presentation No.

Financial support None.

Proprietary interest statement There are no financial interests related to the manuscript, including stock or ownership of a business entity connected to a product described in the paper, paid consulting for the company or competing companies, or patent rights to a drug or piece of equipment.

Open Access This article is distributed under the terms of the Creative Commons Attribution Noncommercial License which permits any noncommercial use, distribution, and reproduction in any medium, provided the original author(s) and source are credited.

\section{References}

1. Kaufman LM, Guay-Bhatia LAG (1998) Monocanalicular intubation with Monoka tubes for the treatment of congenital nasolacrimal duct obstruction. Ophthalmology 105:336-341

2. Freitag SK, Woog JJ (2000) Congenital nasolacrimal obstruction. Ophthalmol Clin North Am 13:705-718

3. Engel JM, Hicuje-Schmidt C, Khammar A, Ostfeld BM, Vyas A, Ticho BH (2007) Monocanalicular silastic intubation bor the initial correction of congenital nasolacrimal duct obstruction. J AAPOS 11:183-186

4. Kashkouli MB, Kempster RC, Galloway GD, Beigi B (2005) Monocanalicular versus bicanalicular silicone intubation for nasolacrimal duct stenosis in adults. Ophthal Plast Reconstr Surg 21:142-147

5. Huang YH, Liao SL, Lin LLK (2009) Balloon dacryocystoplasty and monocanalicular intubation with Monoka tubes in the treatment of congenital nasolacrimal duct obstruction. Graefes Arch Clin Exp Ophthalmol 247:795-799

6. Pashby RC, Hurwitz JJ (1996) Pediatric lacrimal diseases. In: Hurwitz JJ (ed) The lacrimal system, 1st edn. Lippincott Raven, Philadelphia, pp 237-244

7. Fayet B, Assouline M, Bernard JA (1998) Letter to editor (Monocanalicular intubation with Monoka tubes for the treatment of congenital nasolacrimal duct obstruction). Ophthalmology 106:1795-1796

8. Fayet B, Bernard JA (1990) A monocanalicular stent with selfstabilizing meatic fixation in surgery of excretory lacrimal ducts. Initial results. Ophtalmologie 4:351-357

9. Fayet B, Hurbli T, Renard G, Ruban JM, Racy E, Bernard JA (2001) Suggested precautions when using a monocanalicular stent. Ophthal Plast Reconstr Surg 17:76-77

10. Komínek P, Červenka S, Novák V (2000) Intubation of the lacrimal pathways under endoscopic control. Ophthalmologica 214:381-384

11. Repka MX, Melia BM, Beck RW (2008) Primary treatment of nasolacrimal duct obstruction with nasolacrimal duct intubation in children younger than 4 years of age. J AAPOS 12:445-450

12. Dortzbach RK, France TD, Kushner BT, Gonnering RS (1982) Silicone intubation for obstruction of the nasolacrimal duct in children. Am J Ophthalmol 94:585-590

13. Fayet B, Bernard JA, Assouline M (1993) Bicanalicular versus monocanalicular silicone intubation for nasolacrimal duct impatency in children: a comparative study. Orbit 12:149-156 